\title{
Identification of a myometrial molecular profile for dystocic labor
}

\author{
Donal J Brennan ${ }^{1,2}$, Sharon F McGee², Elton Rexhepaj ${ }^{2}$, Darran P O'Connor ${ }^{2}$, Michael Robson ${ }^{1}$ and \\ Colm O'Herlihy ${ }^{3^{*}}$
}

\begin{abstract}
Background: The most common indication for cesarean section (CS) in nulliparous women is dystocia secondary to ineffective myometrial contractility. The aim of this study was to identify a molecular profile in myometrium associated with dystocic labor.

Methods: Myometrial biopsies were obtained from the upper incisional margins of nulliparous women undergoing lower segment CS for dystocia $(n=4)$ and control women undergoing CS in the second stage who had demonstrated efficient uterine action during the first stage of labor $(n=4)$. All patients were in spontaneous (noninduced) labor and had received intrapartum oxytocin to accelerate labor. RNA was extracted from biopsies and hybridized to Affymetrix HuGene U133A Plus 2 microarrays. Internal validation was performed using quantitative SYBR Green Real-Time PCR.
\end{abstract}

Results: Seventy genes were differentially expressed between the two groups. 58 genes were down-regulated in the dystocia group. Gene ontology analysis revealed 12 of the 58 down-regulated genes were involved in the immune response. These included (ERAP2, (8.67 fold change (FC)) HLA-DQB1 (7.88 FC) CD28 (2.60 FC), LILRA3 (2.87 FC) and TGFBR3 (2.1 FC)) Hierarchical clustering demonstrated a difference in global gene expression patterns between the samples from dystocic and non-dystocic labours. RT-PCR validation was performed on 4 genes ERAP2, CD28, LILRA3 and TGFBR3

Conclusion: These findings suggest an underlying molecular basis for dystocia in nulliparous women in spontaneous labor. Differentially expressed genes suggest an important role for the immune response in dystocic labor and may provide important indicators for new diagnostic assays and potential intrapartum therapeutic targets.

\section{Background}

As cesarean section (CS) rates continue to rise throughout the developed world, an improved understanding of the molecular mechanisms underlying parturition at term is urgently required. Between 1974 and 2008 overall cesarean rates increased from $5 \%$ to $19.1 \%$ in the National Maternity Hospital (NMH), Dublin and one of the major contributors to this was a 4-fold increase in cesarean deliveries amongst term singleton cephalic nulliparas (TSCN) [1]. CS rates vary between institutions, although TSCN CS rates correlate with institutional CS rates and we have previously documented that $98 \%$ of

\footnotetext{
* Correspondence: Colm.oherlihy@ucd.ie

${ }^{3}$ UCD School of Medicine and Medical Science, Dublin, Ireland

Full list of author information is available at the end of the article
}

inter-institutional variation in overall CS rates can be attributed to TSCN rates [2], which demonstrates that TSCN as a cohort has a significant impact on cesarean rates within any obstetric population. However, despite much attention within the obstetric literature addressing the timing and mode of twin deliveries [3], vaginal breech delivery [4] and the optimum management of pre-term, growth-restricted fetuses [5], little emphasis has been placed on the management of TSCN, an important group of parturients, which has been relatively neglected hitherto by research initiatives [2].

The most common primary indication for CS is dystocia or slow labor, most commonly secondary to inefficient myometrial contractility. Dystocia is a common obstetric problem, affecting 3-8\% of deliveries [6], and is a particular complication of first pregnancies. In
C Biomed Central

() 2011 Brennan et al; licensee BioMed Central Ltd. This is an Open Access article distributed under the terms of the Creative Commons Attribution License (http://creativecommons.org/licenses/by/2.0), which permits unrestricted use, distribution, and reproduction in any medium, provided the original work is properly cited. 
approximately $40 \%$ of first labors, dystocia can be adequately and safely corrected by intrapartum administration of oxytocin, resulting in vaginal delivery [7]. In 10$20 \%$ of cases of dystocia, however, myometrial response to oxytocin is poor and CS becomes the only safe option following prolonged labor [8]. It is believed this complication is likely to increase mainly due to delayed childbearing and increased prevalence of obesity in the obstetric population both factors which adversely affect intrapartum myometrial contractility $[9,10]$. For every $1 \%$ increase in the incidence of nulliparous CS for dystocia, overall caesarean rates will inevitably increase by at least $0.5 \%$ due to the consequent increase in CS in women with scarred uteri. An improved understanding of the molecular mechanisms underlying dystocic labor and may result in alternative adjuvants to oxytocin.

To date, we are not aware of studies using gene expression profiling to evaluate the physiology and mechanisms underlying dystocia in nulliparous women in spontaneous labor. In a large Swedish population-based study, which examined over two million deliveries, Algovik et al demonstrated a large genetic influence on dystocia [6]. This study estimated that heritability contributed $28 \%$ in the liability of developing primary dystocia, with significant concordance evident amongst monozygotic twins and an increased risk of dystocia in women who had a mother or sister with a history of dystocic labors. Additionally, transgenic knockout mouse models examining prostaglandin F2 $\alpha$ receptor [11] and testosterone 5- $\alpha$-reductase type 1 [12], respectively, exhibit an absence of parturition, although screening for mutations in these candidate dystocia-related genes in humans proved unsuccessful [13]. The genetic basis of dystocia is likely to be more complex that a single gene mutation. Considering the clinical impact of dystocia, a single gene mutation would be subject to purifying selection and would be selected against in the evolutionary process. Therefore genome-wide screening should provide more useful insights. The aim of this study was to use gene expression microarrays to examine the temporal and spatial changes in myometrial gene expression during normally-progressing and dystocic labors to improve our understanding of the molecular mechanisms underlying term dystocic labor.

\section{Methods}

The National Maternity Hospital is a tertiary referral university institution that publishes an Annual Clinical Report, which includes detailed analysis of obstetric outcomes and modes of delivery of all delivered mothers (> 9, 000 annually) and on all perinatal deaths (stillbirths and first-week neonatal deaths of infants who weighed > $500 \mathrm{~g}$, corrected for the exclusion of lethal malformations). Management of nulliparous labor has been standardized in the institution throughout the last four decades according to an Active Management of Labor protocol [8], the principles of which include accurate early diagnosis of labor, early correction of inefficient uterine action, and one to one care by a personal nurse throughout labor [14]. Inefficient uterine action is corrected by the administration of intravenous oxytocin in a concentration of $10 \mathrm{IU} / \mathrm{L}$, when subsequent cervical dilatation does not progress at a rate of at least $1 \mathrm{~cm}$ per hour. Oxytocin acceleration is commenced in a dosage of $5 \mathrm{mU} / \mathrm{min}$, and is increased to a maximum of $30 \mathrm{mU} / \mathrm{min}$ and titrated against the frequency of uterine contractions, which are restricted to 7 contractions in 15 minutes. Progress in all labors is recorded on an individual partogram, which plots cervical dilatation as a function of time, up to a maximum of 12 hours (Figure 1 ). Using this protocol, less than $3 \%$ of women admitted to the NMH remain undelivered after 12 hours, when they are delivered by CS unless delivery is imminent.

Definitions used for this study included: nulliparous: para 0, irrespective of gravidity; term: greater than or equal to 37 completed weeks gestation and singleton gestation, no evidence of a multiple gestation after the first trimester. Representative partograms for both groups used in this study are shown in Figure 1.

\section{Sample Collection}

Patients provided informed consent to partake in this study and ethical approval was obtained from ethics committee in the National Maternity Hospital, Holles Street, Ireland. Myometrial biopsies were obtained from the midpoint of the upper incisional margins of the uteri of women undergoing lower segment CS for dystocia $(n=4)$ and in control women undergoing CS in the second stage, who had demonstrated efficient $(\geq 1 \mathrm{~cm}$ dilatation per hour) uterine action (EUA) during the first stage of labor $(n=4)$. Care was taken to remove decidual tissue. All patients in this group underwent CS for persistent occiput posterior position. A scissors was used to obtain myometrial samples, all of which measured approximately $1 \mathrm{~cm}^{3}$. All patients presented to the labor ward in spontaneous labor with intact membranes and subsequently underwent an amniotomy and intrapartum oxytocin acceleration. All amniotomies were performed at a cervical dilatation of $3 \mathrm{~cm}$ or less. Patient characteristics are outlined in table 1; all were Caucasian with singleton pregnancies, aged less than 35 years. No women developed pyrexia during labor or received prophylactic antibiotics.

Myometrial samples were transferred directly in the operating room into RNALater (Qiagen, Crawley, West Sussex, UK) and stored at $4^{\circ} \mathrm{C}$ for 24 hours. RNALater was then removed and samples were stored at $-80^{\circ} \mathrm{C}$. Total RNA extraction and purification from tissue samples were carried out using TRIzol reagent (Invitrogen, Carlsbad, 

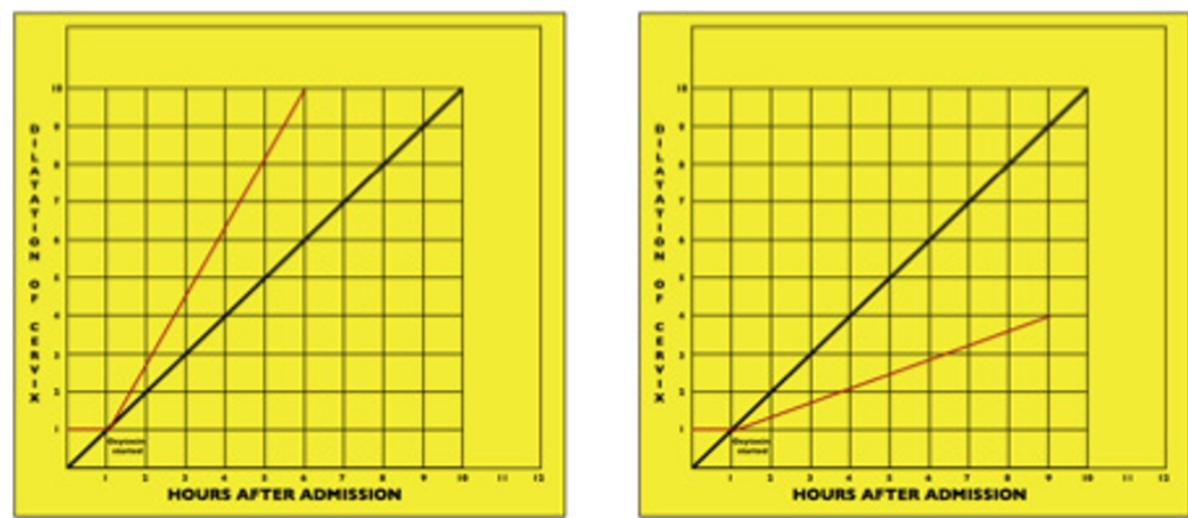

Figure 1 Dystocia and Efficient Uterine Action. Partograms representing dystocia and efficient uterine action.

CA) as per the manufacturer's protocol. Preparation of labeled complementary RNA and hybridization to HGU133 Plus 2.0 GeneChips (Affymetrix, Santa Clara, CA) was performed as per the manufacturer's recommended protocol.

\section{Data Analysis}

Raw data (cel files) were analyzed using Bioconductor 1.9 http://bioconductor.org running on $\mathrm{R} 2.6 .0$ [15]. Normalization was performed using the Affymetrix package's Robust Multichip Average (RMA) default method [16]. Differential gene expression was measured using a modified $t$ test, and genes demonstrating greater than 2 fold difference and a p value $<0.05$ were considered to be differentially expressed. Hierarchical clustering and principal components analysis were performed using MatLab 7 (MathWorks, Apple Hill Drive, MA). Raw data are available in Geo http://www.ncbi.nlm.nih. gov/projects/geo/, accession number GSE32178.

\section{Quantitative SYBR Green Real-Time PCR}

Total RNA was isolated from tissues using Trizol (Invitrogen) and reverse transcribed using SuperScript II ${ }^{\mathrm{TM}}$ Reverse Transcriptase (Invitrogen) according to the manufacturer's instructions. ERAP2 (FW-TGGATGGGACCAACTCATTACA, RV- TGCACCAACTAGCTGA AACAC), CD28 (FW- GGCATCCCTTCACAAAGGACT, RV- CCCCGTTTTTGAGTAAACCTGA), LILRA3 (FWCCAGTGTGTTTCTGATGTCAGC, RV- CCGGATGCACCGAGATGAAG), HLA-DQB1 (FW - AGGGTGAATGTTTCCCCCTC, RV- CTGCCTGGGTAGA AATCCGT) primers were designed using Primer Express software (Applied Biosystems Version 2.0) and used to amplify specific DNA fragments with SYBR Green PCR Master Mix (Applied Biosystems) using a 7900HT Fast Real-Time PCR System (Applied Biosystems). Relative expression levels were calculated using the qBase real-time PCR relative quantification software [17] with all samples normalized to GAPDH expression. Negative controls included a no template control and a no reverse transcriptase control. All qRT-PCR reactions were performed in triplicate.

\section{Results}

Genome-wide transcriptomic analysis was performed on myometrial biopsies taken from the lower uterine segment in Caucasian women undergoing CS for dystocia $(\mathrm{n}=4)$ and in women who demonstrated efficient

Table 1 Patient characteristics

\begin{tabular}{|c|c|c|c|c|c|c|c|c|}
\hline Group & Age & BMI & Parity & Gestation & $\begin{array}{l}\text { Duration } \\
\text { of Labor }\end{array}$ & Epidural & $\begin{array}{c}\text { Cervical } \\
\text { Dilation } \\
\text { at CS }\end{array}$ & $\begin{array}{c}\text { Baby } \\
\text { Weight }\end{array}$ \\
\hline$\overline{\text { Dystocia }}$ & 29 & 22.8 & 0 & $40^{+3}$ & 10hrs & Yes & $2 \mathrm{~cm}$ & $3810 \mathrm{gm}$ \\
\hline Dystocia & 26 & 24.4 & 0 & $41^{+0}$ & $11 \mathrm{hrs}$ & Yes & $4 \mathrm{~cm}$ & $4260 \mathrm{gm}$ \\
\hline Dystocia & 33 & 22.7 & 0 & $41^{+1}$ & 9hrs & Yes & $2 \mathrm{~cm}$ & $2890 \mathrm{gm}$ \\
\hline Dystocia & 27 & 31.2 & 0 & $41^{+1}$ & 6hrs & Yes & $3 \mathrm{~cm}$ & $3710 \mathrm{gm}$ \\
\hline EUA & 25 & 23.4 & 0 & $40^{+6}$ & 10hrs & Yes & $10 \mathrm{~cm}$ & $3145 \mathrm{gm}$ \\
\hline EUA & 31 & 24.3 & 0 & $40^{+5}$ & 6hrs & Yes & $10 \mathrm{~cm}$ & $3440 \mathrm{gm}$ \\
\hline EUA & 32 & 28.7 & 0 & $39^{+3}$ & 8hrs & Yes & $10 \mathrm{~cm}$ & 3930 gm \\
\hline EUA & 30 & 31.0 & 0 & $41^{+5}$ & $8 h r s 30 \mathrm{~min}$ & Yes & $10 \mathrm{~cm}$ & $4840 \mathrm{gm}$ \\
\hline
\end{tabular}

Abbreviations: EUA - efficient uterine action, BMI - body mass index (at booking). 
uterine action in the first stage of labor, but underwent a second stage CS for persistent occiput posterior position. All of the patients included in the study were nulliparas in spontaneous labor between 37 and 42 weeks. There were no differences between the two groups regarding maternal age, $\mathrm{BMI}$, or gestation at delivery (Table 1). The mean birthweight in the dystocic group was 3667 gm compared to 3839 gm in the efficient uterine action group; all patients received epidural anaesthesia.

Unsupervised hierarchical clustering and principal components analysis (PCA) were performed to gain a global view of gene expression in dystocia and efficient myometrium. Probes were filtered based on gene entropy and genes displaying entropy values below the $10^{\text {th }}$ centile were removed prior to hierarchical clustering and PCA. As demonstrated in Figure 2, hierarchical clustering of genes with a high entropy value produced a very distinctive separation between dystocia and EUA. This was confirmed using PCA whereby the four dystocic samples clustered together (Figure 2b), demonstrating that dystocia has a distinctive myometrial molecular profile compared to normally progressing labor.
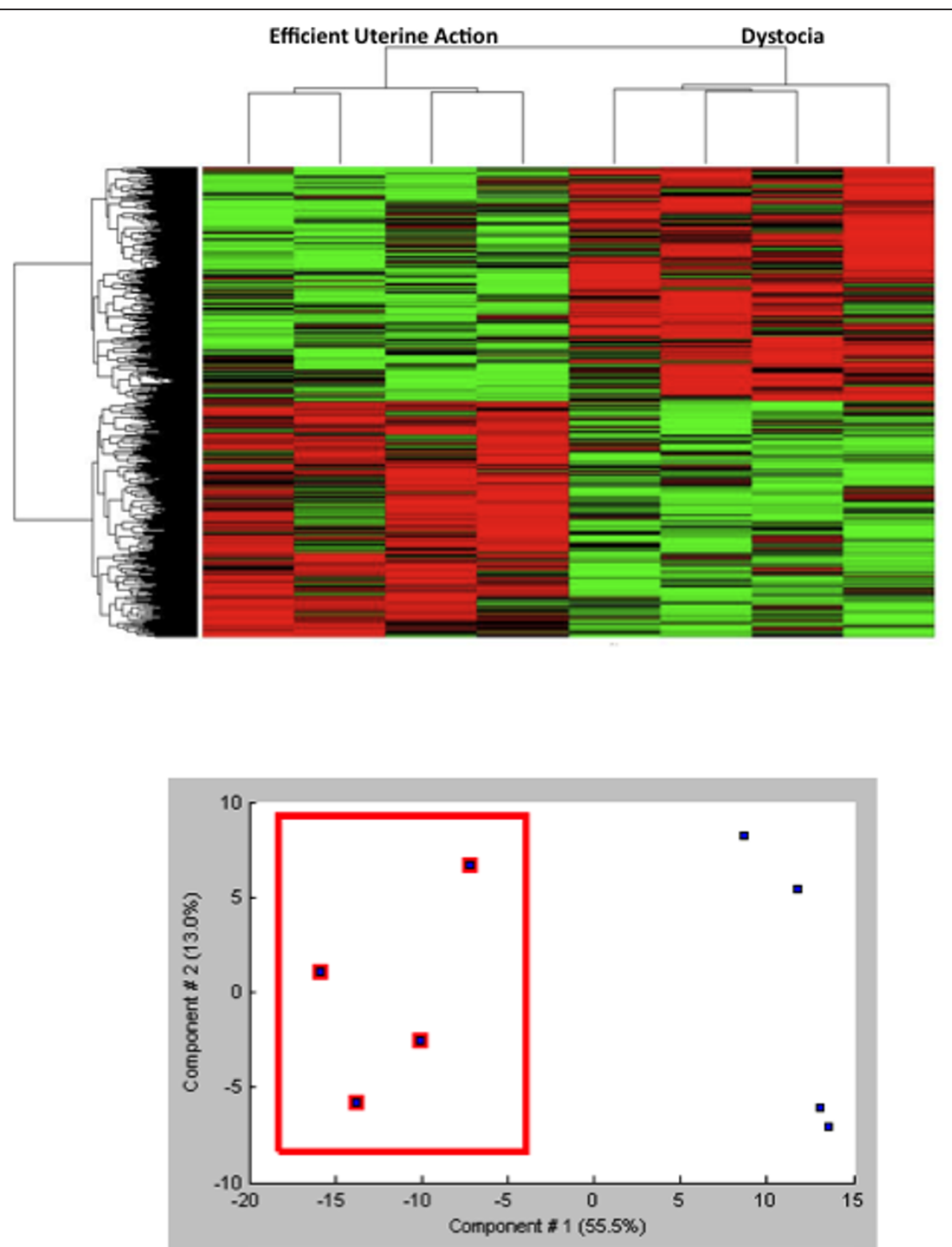

Figure 2 Molecular Profile of Dytocia. Hierarchical clustering demonstrating a distinct dystocia transcriptomic profile (a). Principal components analysis demonstrating aggregation of dystocia specimens. 
To examine the molecular profile of dystocia in more detail, both dystocic and non-dystocic groups were compared to identify differentially expressed genes. Given the relatively small number of samples in both groups, strict thresholds were applied and only genes that exhibited a 2 -fold change and a $p$ value $<0.05$ were considered differentially expressed (Figure 3a). Using this threshold, 70 genes were differentially expressed in women with dystocia compared to efficient uterine action (Table 2). Within the 70 genes, 58 were downregulated and 12 were up-regulated in the dystocic specimens compared to normally progressing labor. Gene ontology analysis revealed that the most common processes in the differentially expressed genes were immune response, transcription and DNA replication (Figure $3 \mathrm{~b}$ ). In particular a number of key regulators of the cell cycle
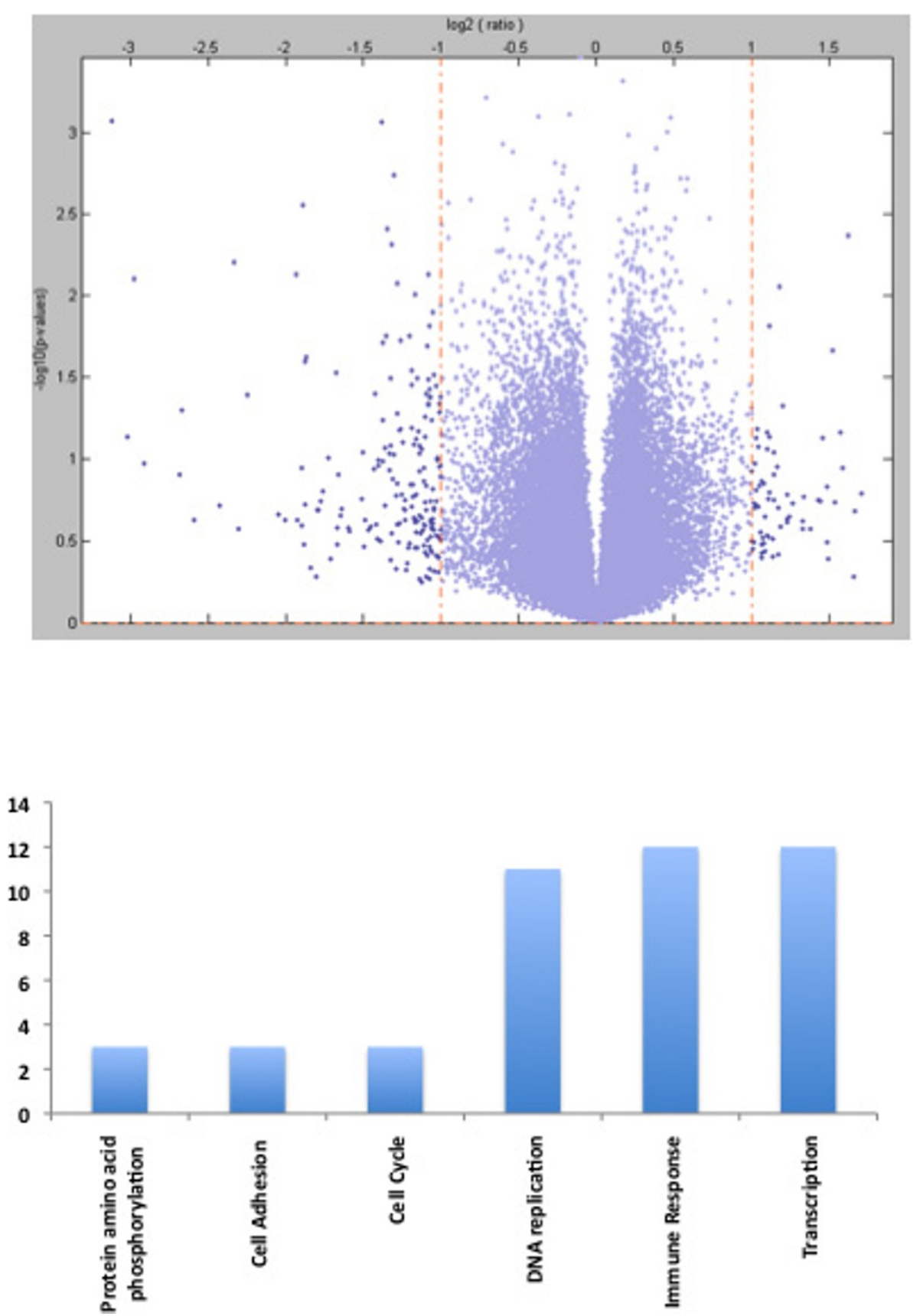

Figure 3 Differentially Expressed Genes. Volcano plot demonstrating differentially expressed genes (a). Gene ontology analysis of differentially expressed genes (b) 
Table 2 Differentially expressed genes in dystocic labor

\begin{tabular}{|c|c|c|c|}
\hline Gene Symbol & Gene Title & Fold Change & $\mathrm{p}$ value \\
\hline ERAP2 & endoplasmic reticulum aminopeptidase 2 & -8.67 & 0.0009 \\
\hline C15orf48 & chromosome 15 open reading frame 48 & -8.11 & 0.0732 \\
\hline HLA-DQB1 & major histocompatibility complex, class II, DQ beta 1 & -7.88 & 0.0079 \\
\hline LOC389831 & hypothetical gene supported by AL713796 & -6.35 & 0.0503 \\
\hline HBG1 & hemoglobin, gamma A & -5.05 & 0.0062 \\
\hline LOC389831 & hypothetical gene supported by AL713796 & -4.75 & 0.0406 \\
\hline CCNE2 & cyclin E2 & -3.71 & 0.0028 \\
\hline KIAA0101 & KIAA0101 & -3.66 & 0.0253 \\
\hline ID2 & inhibitor of DNA binding 2, dominant negative helix-loop-helix protein & -3.08 & 0.0043 \\
\hline C7 & complement component 7 & -2.87 & 0.0217 \\
\hline LILRA3 & leukocyte immunoglobulin-like receptor, subfamily A (without TM domain), member 3 & -2.84 & 0.0916 \\
\hline TRIM13 & tripartite motif-containing 13 & -2.74 & 0.0744 \\
\hline MLF1IP & MLF1 interacting protein & -2.68 & 0.0400 \\
\hline DTL & denticleless homolog (Drosophila) & -2.60 & 0.0009 \\
\hline CD28 & CD28 molecule & -2.60 & 0.0576 \\
\hline LOC283788 & FSHD region gene 1 pseudogene & -2.60 & 0.0195 \\
\hline TFCP2L1 & transcription factor CP2-like 1 & -2.56 & 0.0862 \\
\hline RRM2 & ribonucleotide reductase $\mathrm{M} 2$ & -2.55 & 0.0177 \\
\hline $\mathrm{EV} I 2 \mathrm{~A}$ & ecotropic viral integration site $2 \mathrm{~A}$ & -2.51 & 0.0926 \\
\hline TYMS & thymidylate synthetase & -2.51 & 0.0323 \\
\hline EAF2 & ELL associated factor 2 & -2.47 & 0.0937 \\
\hline ZNF367 & zinc finger protein 367 & -2.46 & 0.0018 \\
\hline MCM4 & minichromosome maintenance complex component 4 & -2.43 & 0.0083 \\
\hline MCM10 & minichromosome maintenance complex component 10 & -2.43 & 0.0527 \\
\hline KLF5 & Kruppel-like factor 5 (intestinal) & -2.41 & 0.0665 \\
\hline CENPK & centromere protein $\mathrm{K}$ & -2.40 & 0.0656 \\
\hline HELLS & helicase, lymphoid-specific & -2.39 & 0.0190 \\
\hline CDC6 & cell division cycle 6 homolog (S. cerevisiae) & -2.37 & 0.0798 \\
\hline TYMS & thymidylate synthetase & -2.30 & 0.0178 \\
\hline GZMH & granzyme H (cathepsin G-like 2, protein h-CCPX) & -2.29 & 0.0473 \\
\hline DDX17 & DEAD (Asp-Glu-Ala-Asp) box polypeptide 17 & -2.28 & 0.0648 \\
\hline MRPL43 & mitochondrial ribosomal protein $L 43$ & -2.26 & 0.0089 \\
\hline HAMP & hepcidin antimicrobial peptide & -2.26 & 0.0816 \\
\hline MCM2 & minichromosome maintenance complex component 2 & -2.25 & 0.0099 \\
\hline GAPT & GRB2-binding adaptor protein, transmembrane & -2.24 & 0.0757 \\
\hline RRAGD & Ras-related GTP binding D & -2.22 & 0.0683 \\
\hline TREM2 & triggering receptor expressed on myeloid cells 2 & -2.20 & 0.0921 \\
\hline PBK & PDZ binding kinase & -2.18 & 0.0865 \\
\hline SVEP1 & sushi, von Willebrand factor type A, EGF and pentraxin domain containing 1 & -2.17 & 0.0733 \\
\hline TGFBR3 & transforming growth factor, beta receptor III & -2.16 & 0.0155 \\
\hline PPAP2A & phosphatidic acid phosphatase type $2 \mathrm{~A}$ & -2.15 & 0.0684 \\
\hline UHRF1 & ubiquitin-like with PHD and ring finger domains 1 & -2.14 & 0.0738 \\
\hline TFEC & transcription factor EC & -2.14 & 0.0551 \\
\hline PLEKHG1 & pleckstrin homology domain containing, family G (with RhoGef domain) member 1 & -2.14 & 0.0874 \\
\hline ZWILCH & Zwilch, kinetochore associated, homolog (Drosophila) & -2.13 & 0.0400 \\
\hline SPA17 & sperm autoantigenic protein 17 & -2.12 & 0.0464 \\
\hline STK17B & serine/threonine kinase $17 \mathrm{~b}$ & -2.12 & 0.0461 \\
\hline FCGR1A & Fc fragment of lgG, high affinity la, receptor (CD64) & -2.12 & 0.0324 \\
\hline MAFIP & MAFF interacting protein & -2.10 & 0.0154 \\
\hline BUB1B & budding uninhibited by benzimidazoles 1 homolog beta (yeast) & -2.10 & 0.0420 \\
\hline RRM2 & ribonucleotide reductase $\mathrm{M} 2$ & -2.10 & 0.0415 \\
\hline
\end{tabular}


Table 2 Differentially expressed genes in dystocic labor (Continued)

\begin{tabular}{llcc}
\hline BHLHE41 & basic helix-loop-helix family, member e41 & -2.07 & 0.0126 \\
MCM5 & minichromosome maintenance complex component 5 & -2.06 & 0.0305 \\
ATP8B1 & ATPase, aminophospholipid transporter, class I, type 8B, member 1 & -2.05 & 0.0653 \\
UBE2T & ubiquitin-conjugating enzyme E2T (putative) & -2.05 & 0.0358 \\
ATAD2 & ATPase family, AAA domain containing 2 & -2.03 & 0.0980 \\
OXR1 & oxidation resistance 1 & -2.02 & 0.0456 \\
EZR & ezrin & -2.00 & 0.0416 \\
PPAP2A & phosphatidic acid phosphatase type 2A & 2.04 & 0.0741 \\
AQP3 & aquaporin 3 (Gill blood group) & 2.06 \\
MAD2L1 & MAD2 mitotic arrest deficient-like 1 (yeast) & 2.08 \\
GIN1 & gypsy retrotransposon integrase 1 & 2.11 & 0.0844 \\
RGS17 & regulator of G-protein signaling 17 & 2.12 & 0.0582 \\
LOC642236 & similar to FRG1 protein (FSHD region gene 1 protein) & 0.0373 \\
ITGB3BP & integrin beta 3 binding protein (beta3-endonexin) & 2.13 \\
POPDC3 & popeye domain containing 3 & 2.22 & 0.0074 \\
FCGR1B & FC fragment of lgG, high affinity lb, receptor (CD64) & 2.28 & 0.0203 \\
LOC253039 & hypothetical LOC253039 & 0.0323 \\
PRIM1 & primase, DNA, polypeptide 1 (49kDa) & 0.0289 \\
CLDN10 & claudin 10 & 2.28 & 0.0350 \\
\hline
\end{tabular}

were down-regulated in the dystocic samples such as cyclin E, CENPK and ID2, all of which promote progression through the cell cycle.

As the majority of dystocia-related genes were downregulated, these genes were examined in detail. A significant proportion of genes in this group were associated with inflammation and immune response. To validate our findings, qRT-PCR was performed on four of the immune response genes: ERAP2 and HLADQB1, both of which play key roles in antigen presentation; CD28, a key regulator of the $\mathrm{TH} 2 \mathrm{~T}$ cell response and LILRA3, a regulator of monocyte and $\mathrm{B}$ cell activation. qRT-PCR confirmed that all four genes were down-regulated in dystocia compared to normally progressing labor (Figure 4).

\section{Discussion}

Although dystocia represents one of the major indications for primary CS, to our knowledge, genome-wide analysis has not been applied to the study of the molecular mechanisms underlying dystocia in term nulliparous labor. High-throughput screening technologies, such as DNA microarrays have been used to improve comprehension of the major structural and metabolic transformations, which affect the myometrium from the very beginning of pregnancy until the onset of labor [18-22]. Changes in the structural and contractile genes associated with the actin cytoskeleton, focal adhesion molecules, adherens and tight junctions represent a large subset of genes that are over-expressed in pregnant, compared to non-pregnant, human myometrium [18]. Additionally, in an attempt to further decipher the causes of pre-term labor, a number of investigators have used transcriptomic approaches to examine the transition from uterine quiescence to the onset of contractions in small numbers of patients [18-22]. These studies identified a number of genes, which may be useful in predicting pre-term labor; however, none have specifically examined dystocia. Our findings demonstrate significant differences in the myometrial transcriptomic profiles of dystocic as compared to normally-progressing labors. In particular, we have demonstrated that a number of key regulators of the host immune response are down-regulated in dystocia.

The strengths of this study are mainly based around the study design whereby the inclusion criteria were strict. Patients included in this study were nulliparas in spontaneous labor. All women in the dystocia group received $30 \mathrm{mU} / \mathrm{min}$ oxytocin for at least 4 hours. In addition the study was performed in a unit where the diagnosis and management of spontaneous nulliparous labor has been standardized for the last four decades [14]. A major weakness of this study is the small number of samples studied. In addition, sampling the lower segment alone may give a true global description of the dystocic transcriptome. Transcriptomic profiling has shown different myometrial gene expression patterns in lower segment compared to fundal biopsies in labour $[22,23]$, however the majority of these studies appear to have been performed in multiparous patients and thus these finds may not be applicable to our study. Dystocia, due to ineffective myometrial contractility is much more common in women undergoing induction of labor, although induced labors were specifically excluded from 


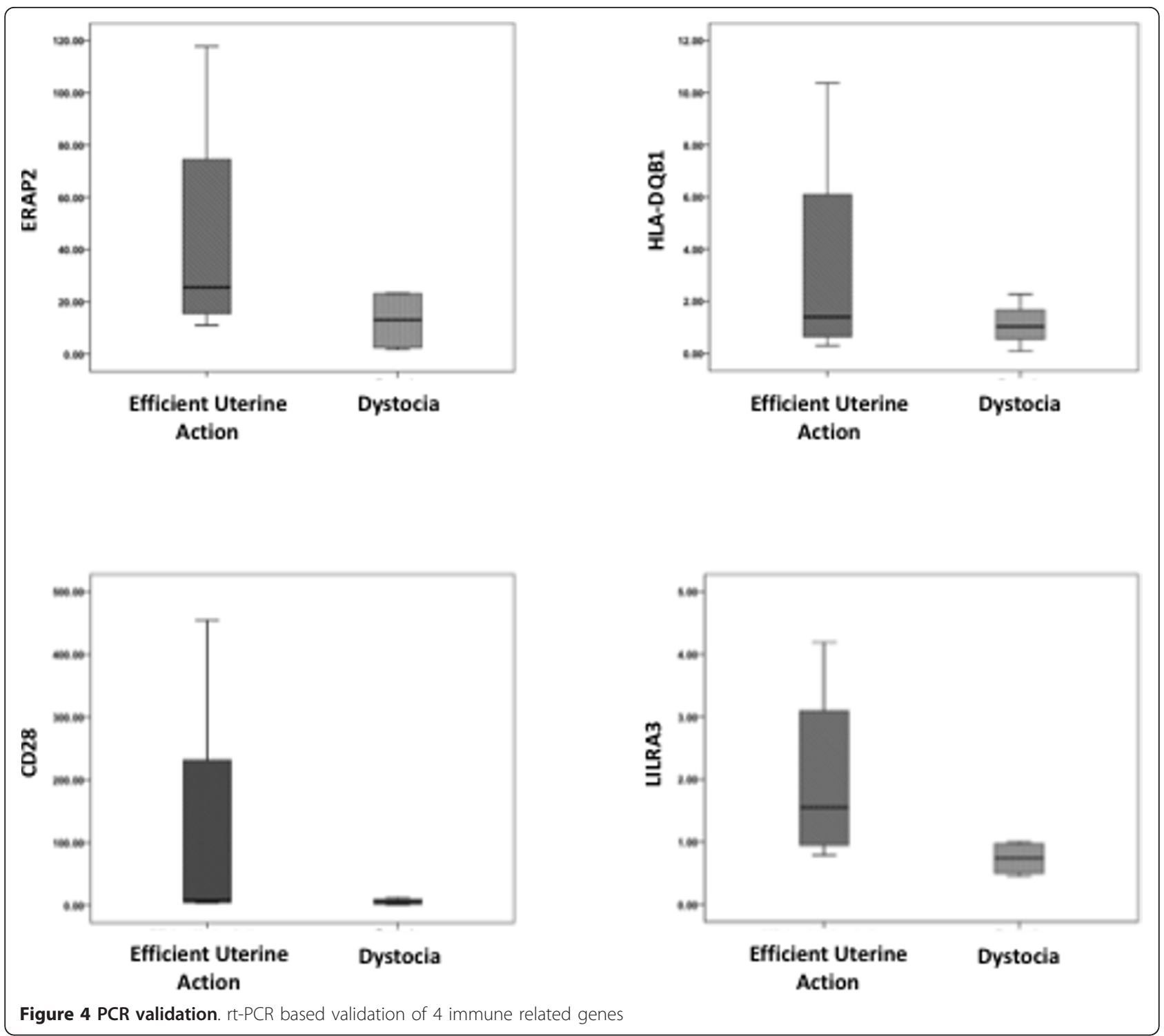

this study in an attempt to compare two homogenous groups. Also the indication for induction is important as a woman undergoing labor induction following a prolonged interval of ruptured membranes is likely to have a different myometrial profile to a patient being induced for pre-eclampsia. The absence of an independent validation cohort represents another weakness of this study, although internal validation using rt-PCR was performed to address this issue.

This study further strengthens the potential argument for an underlying genetic predisposition for dystocia $[6,24]$. The finding that the majority of differentially expressed genes were down-regulated suggests that many of these may harbour loss-of-function mutations. The association of dystocia with an impaired immune response is also in agreement with a larger recent study by Mittal et al [25], who demonstrated increased expression of a number of inflammatory genes in patients with arrest of descent in the second stage, a cohort similar to the efficient uterine action group in our study. Comparison of our findings to those of Mittal et al [25] should be tempered by the fact that their study did not stratify for parity or mode of onset of labor. The importance of the inflammatory response in spontaneous labor cannot be overstated, since Unal et al [26] recently demonstrated that maternal inflammatory markers increase before the onset of spontaneous labor, suggesting that any future studies of dystocia should be stratified according to labor onset (spontaneous versus induced). Similarly, dystocia in a multiparous woman is much more likely to be secondary to obstruction than inefficient uterine action and thus likely to have a different 
underlying molecular profile, emphasizing the need for stratification by parity.

The identification of ERAP2 as a gene that was significantly down-regulated in dystocia is of particular interest because ERAP2 has been identified as a genetic susceptibility locus for preeclampsia in a number of different populations $[27,28]$. Although ERAP2 is considered to be a member of the oxytocinase subfamily of M1 aminopeptidases, it has no hydrolytic activity towards oxytocin [29]. ERAP2 which is regulated by interferon gamma appears to play a key role in the innate immune response whereby it trims various $\mathrm{N}$ terminal extended precursors to major histocompatibility complex class I-presented antigenic peptides [29]. Although a number of missense single nucleotide polymorphisms (SNP) in ERAP2 have been associated with an increased risk of preeclampsia $[27,28]$, the functional importance of these SNPs is still not fully understood. A recent study did however demonstrate that specific ERAP2 haplotypes are associated with lower levels of MHC class I expressed on the surface of B cells, suggesting that naturally occurring ERAP2 deficiency affects MHC presentation and immune response [30].

Although historical studies have suggested that labor may be easier to induce in preeclamptic patients $[31,32]$, a number of recent reports have suggested that women with preeclampsia undergoing labor induction have higher cesarean delivery rates compared with non-preeclamptics, independent of parity or gestational age [33-35]. In a large retrospective cohort study, Kim et al demonstrated a significantly higher term nulliparous CS rate in induced preeclamptic patients compared to healthy controls [33]. While our study was conducted on nulliparas in spontaneous term labour these findings raise intriguing questions about the role of ERAP2 and efficient uterine action in preeclamptic patients, which warrant further investigation.

\section{Conclusion}

Our study demonstrates an obvious difference in the myometrial transcriptomic profiles in women with dystocia and efficient uterine action but it also raises a number of questions. It is currently not possible to predict which women will develop dystocia before the onset of spontaneous labor. Due to the invasive nature of a biopsy, it would not be possible to reduce a myometrial profile to clinical utility, but it is worth noting that two of the genes significantly down-regulated in dystocic patients, ERAP2 and LILRA3, code for secreted proteins which could potentially be detected in human plasma. LILRA3 has previously been detected in rheumatoid arthritis [36]. Nevertheless, the advent of whole genome sequencing offers a platform to further investigate dystocia and to identify the genetic determinants of this complex condition, which is central to ever-increasing international CS rates and thus represents a major current public health issue.

\section{Funding}

The study was funded by the National Maternity Hospital Research Fund

\section{Author details}

${ }^{1}$ National Maternity Hospital, Dublin , Ireland. ${ }^{2}$ UCD School of Biomolecular and Biomedical Science, UCD Conway Institute, Dublin , Ireland. ${ }^{3}$ UCD School of Medicine and Medical Science, Dublin, Ireland.

\section{Authors' contributions}

DJB conceived the study, collected the samples, performed statistical analysis and drafted the manuscript, SMG processed the samples and performed RT-PCR, ER performed statistical analysis, DOC performed RT-PCR, MR conceived the study, provided samples and drafted the manuscript, $\mathrm{COH}$ conceived the study, provided the samples and drafted the manuscript. All authors read and approved the final manuscript.

\section{Authors information}

$D J B, M R$ and $\mathrm{COH}$ are obstetricians and gynaecologists. DJB, SMG, ER and $\mathrm{DOC}$ are research scientists with an interest in biomarker identification and validation

\section{Competing interests}

The authors declare that they have no competing interests.

Received: 11 August 2011 Accepted: 16 October 2011 Published: 16 October 2011

\section{References}

1. Brennan DJ, Murphy M, Robson MS, O'Herlihy C: The singleton, cephalic, nulliparous woman after 36 weeks of gestation: contribution to overall cesarean delivery rates. Obstet Gynecol 2011, 117(2 Pt 1):273-279.

2. Brennan DJ, Robson MS, Murphy M, O'Herlihy C: Comparative analysis of international cesarean delivery rates using 10-group classification identifies significant variation in spontaneous labor. Am J Obstet Gynecol 2009, 201(3):308-e301, 308.

3. Lee YM, Wylie BJ, Simpson LL, D'Alton ME: Twin chorionicity and the risk of stillbirth. Obstet Gynecol 2008, 111(2 Pt 1):301-308.

4. Hannah ME, Hannah WJ, Hewson SA, Hodnett ED, Saigal S, Willan AR: Planned caesarean section versus planned vaginal birth for breech presentation at term: a randomised multicentre trial. Term Breech Trial Collaborative Group. Lancet 2000, 356(9239):1375-1383.

5. Riskin A, Riskin-Mashiah S, Bader D, Kugelman A, Lerner-Geva L, Boyko V, Reichman B: Delivery mode and severe intraventricular hemorrhage in single, very low birth weight, vertex infants. Obstet Gynecol 2008, 112(1):21-28.

6. Algovik M, Nilsson E, Cnattingius S, Lichtenstein P, Nordenskjold A, Westgren M: Genetic influence on dystocia. Acta Obstet Gynecol Scand 2004, 83(9):832-837.

7. Cahill DJ, Boylan PC, O'Herlihy C: Does oxytocin augmentation increase perinatal risk in primigravid labor? Am J Obstet Gynecol 1992, 166(3):847-850.

8. O'Driscoll K, Jackson RJ, Gallagher JT: Prevention of prolonged labour. $\mathrm{Br}$ Med J 1969, 2(5655):477-480.

9. Lynch CM, Sexton DJ, Hession M, Morrison JJ: Obesity and mode of delivery in primigravid and multigravid women. Am J Perinatol 2008, 25(3):163-167.

10. Treacy A, Robson M, O'Herlihy C: Dystocia increases with advancing maternal age. American journal of obstetrics and gynecology 2006, 195(3):760-763.

11. Sugimoto $Y$, Yamasaki A, Segi E, Tsuboi K, Aze $Y$, Nishimura T, Oida $H$, Yoshida N, Tanaka T, Katsuyama M, et al: Failure of parturition in mice lacking the prostaglandin F receptor. Science 1997, 277(5326):681-683. 
12. Mahendroo MS, Cala KM, Landrum DP, Russell DW: Fetal death in mice lacking 5alpha-reductase type 1 caused by estrogen excess. In Molecular endocrinology. Volume 11. Baltimore, Md; 1997:(7):917-927.

13. Algovik M, Lagercrantz J, Westgren $M$, Nordenskjold A: No mutations found in candidate genes for dystocia. In Human reproduction. Volume 14. Oxford, England; 1999:(10):2451-2454.

14. O'Driscoll K, Meagher D, Robson M: The active management of labor. New York: Mosby Year Book Limited; 2004.

15. Team RDC: $A$ language and environment for statistical computing. $R$ Foundation for Statistical Computing 2008.

16. Gautier L, Cope L, Bolstad BM, Irizarry RA: affy-analysis of Affymetrix GeneChip data at the probe level. Bioinformatics 2004, 20(3):307-315.

17. Dolle L, Adriaenssens E, El Yazidi-Belkoura I, Le Bourhis X, Nurcombe V, Hondermarck $\mathrm{H}$ : Nerve growth factor receptors and signaling in breast cancer. Curr Cancer Drug Targets 2004, 4(6):463-470.

18. Breuiller-Fouche M, Germain G: Gene and protein expression in the myometrium in pregnancy and labor. In Reproduction. Volume 131. Cambridge, England; 2006:(5):837-850.

19. Esplin MS, Fausett MB, Peltier MR, Hamblin S, Silver RM, Branch DW, Adashi EY, Whiting D: The use of cDNA microarray to identify differentially expressed labor-associated genes within the human myometrium during labor. American journal of obstetrics and gynecology 2005, 193(2):404-413.

20. Havelock JC, Keller P, Muleba N, Mayhew BA, Casey BM, Rainey WE, Word RA: Human myometrial gene expression before and during parturition. Biology of reproduction 2005, 72(3):707-719.

21. Charpigny G, Leroy MJ, Breuiller-Fouche M, Tanfin Z, Mhaouty-Kodja S Robin P, Leiber D, Cohen-Tannoudji J, Cabrol D, Barberis C, et al: A functional genomic study to identify differential gene expression in the preterm and term human myometrium. Biology of reproduction 2003, 68(6):2289-2296

22. Bukowski R, Hankins GD, Saade GR, Anderson GD, Thornton S: Laborassociated gene expression in the human uterine fundus, lower segment, and cervix. PLOS medicine 2006, 3(6):e169.

23. Havelock J, Keller P, Muleba N, Mayhew B, Casey B, Rainey W, Word R: Human myometrial gene expression before and during parturition. Biology of reproduction 2005, 72(3):707-719.

24. Berg-Lekås ML, Högberg U, Winkvist A: Familial occurrence of dystocia. Am J Obstet Gynecol 1998, 179(1):117-121.

25. Mittal P, Romero R, Tarca AL, Draghici S, Nhan-Chang CL, Chaiworapongsa T, Hotra J, Gomez R, Kusanovic JP, Lee DC, et al: A molecular signature of an arrest of descent in human parturition. Am $\mathrm{J}$ Obstet Gynecol 2011, 204(2):177-e115, 133.

26. Unal ER, Cierny JT, Roedner C, Newman R, Goetzl L: Maternal inflammation in spontaneous term labor. Am J Obstet Gynecol 2011, 204(3):223-e221, 225.

27. Johnson MP, Roten LT, Dyer TD, East CE, Forsmo S, Blangero J, Brennecke SP, Austgulen R, Moses EK: The ERAP2 gene is associated with preeclampsia in Australian and Norwegian populations. Hum Genet 2009, 126(5):655-666.

28. Hill LD, Hilliard DD, York TP, Srinivas S, Kusanovic JP, Gomez R, Elovitz MA, Romero R, Strauss JF: Fetal ERAP2 variation is associated with preeclampsia in African Americans in a case-control study. BMC Med Genet 2011, 12(1):64.

29. Tanioka T, Hattori A, Masuda S, Nomura Y, Nakayama H, Mizutani S, Tsujimoto M: Human leukocyte-derived arginine aminopeptidase. The third member of the oxytocinase subfamily of aminopeptidases. $J$ Biol Chem 2003, 278(34):32275-32283.

30. Andres AM, Dennis MY, Kretzschmar WW, Cannons JL, Lee-Lin SQ, Hurle B, Schwartzberg PL, Williamson SH, Bustamante CD, Nielsen R, et al: Balancing selection maintains a form of ERAP2 that undergoes nonsense-mediated decay and affects antigen presentation. PLoS Genet 2010, 6(10):e1001157.

31. Taylor ES, Bruns PD, Anker RM, Drose VE: Correlation of urinary estrogenpregnanediol excretion with uterine motility during pregnancy. Am J Obstet Gynecol 1955, 70(4):894-909.

32. Zuspan FP, Talledo E: Factors affecting delivery in eclampsia: the condition of the cervix and uterine activity. Am J Obstet Gynecol 1968, 100(5):672-685.

33. Kim LH, Cheng YW, Delaney S, Jelin AC, Caughey AB: Is preeclampsia associated with an increased risk of cesarean delivery if labor is induced? J Matern Fetal Neonatal Med 2010, 23(5):383-388.
34. Ben-Haroush A, Yogev Y, Glickman H, Kaplan B, Hod M, Bar J: Mode of delivery in pregnant women with hypertensive disorders and unfavorable cervix following induction of labor with vaginal application of prostaglandin E. Acta Obstet Gynecol Scand 2005, 84(7):665-671.

35. Xenakis EM, Piper JM, Field N, Conway D, Langer O: Preeclampsia: is induction of labor more successful? Obstetrics and gynecology 1997, 89(4):600-603.

36. An H, Chandra V, Piraino B, Borges L, Geczy C, McNeil HP, Bryant K, Tedla N: Soluble LILRA3, a potential natural antiinflammatory protein, is increased in patients with rheumatoid arthritis and is tightly regulated by interleukin 10, tumor necrosis factor-alpha, and interferon-gamma. J Rheumatol 2010, 37(8):1596-1606.

\section{Pre-publication history}

The pre-publication history for this paper can be accessed here: http://www.biomedcentral.com/1471-2393/11/74/prepub

doi:10.1186/1471-2393-11-74

Cite this article as: Brennan et al:: Identification of a myometrial molecular profile for dystocic labor. BMC Pregnancy and Childbirth 2011 $11: 74$.

\section{Submit your next manuscript to BioMed Central and take full advantage of:}

- Convenient online submission

- Thorough peer review

- No space constraints or color figure charges

- Immediate publication on acceptance

- Inclusion in PubMed, CAS, Scopus and Google Scholar

- Research which is freely available for redistribution 